\title{
ANALISIS PENDAPATAN AGROINDUSTRI NATA DE COCO (Studi kasus di Desa Bojongmengger Kecamatan Cijeungjing Kabupaten Ciamis)
}

\author{
DUDI $^{1 *}$, DANI LUKMAN HAKIM ${ }^{1}$, SUDRADJAT ${ }^{1}$ \\ ${ }^{1}$ Fakultas Pertanian Universitas Galuh \\ *Email : dudiciamis@gmail.com
}

\begin{abstract}
ABSTRAK
Penelitian agroindustri nata de coco ini bertujuan untuk mengetahui: 1) Biaya yang dikeluarkan per satu kali proses produksi oleh perajin agroindustri nata de coco Desa Bojongmengger, 2) Jumlah penerimaan per satu kali proses produksi dari hasil agroindustri nata de coco Desa Bojongmengger, dan 3) Jumlah pendapatan yang diterima per satu kali prpses produksi oleh perajin agroindustri nata de coco Desa Bojongmengger. Penelitian ini menggunakan metode studi kasus. Penarikan sampel dengan menggunakan metode purposive sampling, jadi satu orang dipilih sebagai penghasil agroindustri nata de coco. Data yang digunakan yaitu data primer dan sekunder. Hasilnya menunjukkan bahwa 500 liter air kelapa dan 600 liter air limbah tahu dihasilkan 850 kilogram nata de coco per satu kali proses produksi. Berdasarkan perhitungan diketahui bahwa biaya produksi adalah Rp 1.415.611,57 penerimaan adalah Rp 1.700.000,00 dan pendapatan Rp 284.388,43.
\end{abstract}

Kata Kunci : Agroindustri, biaya, Pendapatan, penerimaan

\section{ABSTRACT}

The objectives of the study were to know : 1) The costs incurred at the Nata De Coco Agroindustry. 2) The amount of revenue the Nata De Coco Agroindustry. 3) The amount of income in the Nata De Coco Agroindustry. The method used in this study was a case study method. The respondent was taken by purposive sampling method, thus one person was chosen as a producer of nata de coco agroindustry. In one product process, the result knowed that 500 liter of coconut water and 600 liter of tofu waswater produced, $850 \mathrm{~kg}$ nata de coco. Base on the calculation known that the production cost was $R p$ 1.415.611,57 the revenue was $R p$ 1.700.000,00 and income was $R p$ 284.388,43.

Keywords: Agroindustry, cost, income, revenues

\section{PENDAHULUAN}

\section{Latar Belakang}

Belakang ini pemanfaatan air

kelapa di Indonesia sudah mulai nampak, khususnya nata de coco. Hal itu ditandai dengan maraknya minuman nata de coco yang dikemas dalam berbagai tampilan yang beredar dipasaran. Rasa khas nata de coco juga menjadi lebih enak bila dicampurkan dengan es buah, kolek, es krim atau lainnya. Sebenarnya Nata de coco untuk manusia tidak mempunyai nilai gizi yang berarti, produk ini namun dapat dipakai untuk keperluan diet, karena termasuk salah satu sumber makanan yang rendah energi (Windro, 2007).

Buah kelapa melihat dari umurnya dibedakan menjadi tiga kelompok yaitu kelapa muda yang umurnya sekitar 6-8 bulan, kelapa setengah tua berumur sekitar 10-11 bulan, dan kelapa tua berumur sekitar 11-13 bulan. Perbedaan daging buah kelapa muda dengan kelapa tua yaitu dari kandungan minyaknya. Bahan minuman penyegar dan merupakan limbah industri kopra menggunakan air kelapa tua. 
Namun demikian dapat dimanfaatkan lagi sebagai bahan campuran minuman penyegar yaitu semacam jelly yang disebut nata de coco (Vita, 2016).

Berdasarkan data dari dinas pertanian dan ketahanan pangan Kabupaten Ciamis bahwa produksi kelapa pada tahun 2018 sebanyak $37.870,24$ ton kelapa dengan luas areal 66.915,07 hektar dan mempunyai kemampuan berproduksi sepanjang tahun secara terus-menerus. Melihat produksi dan kemampuan bahan baku kelapa di Kabupaten Ciamis yang cukup tinggi maka peluang usaha sangatlah terbuka untuk mengembangkan agroindustri nata de coco.

Agroindustri nata de coco di Kabupaten Ciamis sudah lama berdiri dan menurut data dari Dinas Perindustrian dan Perdagangan Kabupaten Ciamis (2019), terdapat 4 unit usaha agroindustri nata de coco yang tersebar di 2 kecamatan yaitu Kecamatan Banjarasari memproduksi sebanyak 1.400 ton/tahun dan Kecamatan Cijeungjing sebanyak 187 ton/tahun. Kecamatan Cijeungjing merupakan agroindustri nata de coco yang kapasitas produksinya terkecil di Kabupaten Ciamis dengan 2 perajin.

Agroindustri nata de coco di Kecamatan Cijeungjing diusahakan di dua desa yang terdiri satu perajin di setiap desanya yaitu terdapat di Desa Bojongmengger dan Desa Utama untuk lebih jelasnya bisa dilihat pada Tabel dibawah.

Data Agroindustri Nata De Coco, Kapasitas Produksi dan Tenaga Kerja di Kecamatan Cijeungjing Tahun 2018

\begin{tabular}{cccccc}
\hline $\begin{array}{c}\mathbf{N} \\
\mathbf{0}\end{array}$ & Desa & $\begin{array}{c}\text { Jumlah } \\
\text { Industri } \\
\text { (Unit) }\end{array}$ & $\begin{array}{c}\text { Kapasitas } \\
\text { Produksi/ } \\
\text { Tahun (Ton) }\end{array}$ & $\begin{array}{c}\text { Tenaga } \\
\text { Kerja } \\
\text { (Orang) }\end{array}$ \\
\hline 1 & Bojongmengger & 1 & 72 & 5 \\
2 & Utama & 1 & 115 & 7 \\
& Jumlah & $\mathbf{2}$ & $\mathbf{1 8 7}$ & $\mathbf{1 2}$ \\
\hline
\end{tabular}

Sumber: Kecamatan Cijeungjing, 2019

Berdasarkan Tabel diketahui bahwa yang memiliki kapasitas produksi nata de coco terkecil di Kecamatan Cijeungjing yaitu berada di Desa Bojongmengger dengan jumlah produksinya 72 ton/tahun. Oleh karena itu, sebagian besar pelaku agroindustri di Indonesia terutama agroindustri skala kecil, menyebabkan besarnya pendapatan sebenarnya yang mereka peroleh tidak bisa diketahui secara pasti karena jarang memperhitungkan secara terperinci seperti biaya yang dikeluarkan dalam usahanya. Bahkan banyak pelaku agroindustri keuangan perusahaan dengan keuangan rumah tangga yang tercampur. Usaha pembuatan nata de coco mempunyai peluang ekonomi yang cukup besar untuk terus dikembangkan, karena masih mempunyai pangsa pasar yang sangat luas. 
Sehubungan dengan latar belakang, maka penulis tertarik untuk melaksanakan penelitian mengenai 'Analisis Pendapatan Agroindustri Nata De Coco yang Merupakan Studi Kasus di Desa Bojongmengger Kecamatan Cijeungjing Kabupaten Ciamis".

Penelitian ini bertujuan untuk mengetahui:

1) Biaya dalam satu kali proses produksi yang dikeluarkan pada agroindustri nata de coco di Desa Bojongmengger Kecamatan Cijeungjing Kabupaten Ciamis

2) Penerimaan dalam satu kali proses produksi pada agroindustri nata de coco di Desa Bojongmengger Kecamatan Cijeungjing Kabupaten Ciamis.

3) Pendapatan dalam satu kali proses produksi pada agrindustri nata de coco di Desa Bojongmengger Kecamatan Cijeungjing Kabupaten Ciamis.

\section{METODE PENELITIAN}

\section{Jenis Penelitian}

Jenis penelitian pada Agroindustri Nata De Coco di Desa Bojongmengger Kecamatan Cijeungjing Kabupaten Ciamis menggunakan studi kasus. Studi kasus yaitu suatu penelitian yang bersifat mendalam mengenai suatu karakteristik tertentu dari objek penelitian (Nazir, 2011).

\section{Teknik Pengumpulan Data}

1) Data primer yaitu data yang diperoleh secara langsung dari perusahaan dan dijadikan responden melalui wawancara, dengan bantuan kuesioner yang telah dipersiapkan.

2) Data sekunder yang diperoleh dari data lembaga-lembaga terkait dengan penelitian ini dan dari studi literatur.

\section{Teknik Penarikan Sampel}

Penarikan sampel perusahaan dalam penelitian ini dilakukan dengan cara penentuan sampel dengan tujuan tertentu (purposive sampling). Purposive sampling yaitu penentuan sampel yang dipandang dapat memberikan data secara maksimal dan adanya pertimbangan tertentu (Arikunto, 2006).

Maka pemilihan kelompok subjek didasarkan atas ciri atau sifat populasi yang sudah diketahui sebelumnya yang mempunyai sangkut paut yang erat. Agar bisa memberikan nilai tambah dari komoditi kelapa, yang pada akhirnya akan memberikan keuntungan dari kegiatan usaha tersebut.

Agroindustri nata de coco di Desa Bojongmengger sengaja dipilih sebagai sampel dengan pertimbangan agroindustri 
tersebut merupakan agroindustri satusatunya di Desa Bojongmengger. Selain itu, usaha nata de coco sudah lama berdiri dan merupakan agroindustri yang produksinya terkecil di tingkat Kecamatan.

\section{Rancangan Analisis Data}

1) Analisis Biaya

Rumus untuk mengetahui besarnya biaya total (total cost) menurut Suratiyah (2015):

TFC + TVC $=$ TC

Dimana:

TC = Biaya Total

TFC = Biaya Tetap Total

TVC = Biaya Variabel Total

2) Analisis penerimaan

Rumus untuk mengetahui besarnya penerimaan menurut Suratiyah (2015):

$\mathbf{Y} \times \mathbf{P y}=\mathbf{T R}$

Dimana:

TR = Penerimaan Total

$\mathrm{Y} \quad=$ Jumlah Produksi

Py $\quad=$ Harga

3) Analisis Pendapatan

Rumus untuk mengetahui besarnya pendapatan menurut Suratiyah (2015):

$$
\mathbf{T R}-\mathbf{T C}=\mathbf{P d}
$$

Dimana:

$\begin{array}{ll}\text { Pd } & =\text { Pendapatan } \\ \text { TR } & =\text { Penerimaan Total } \\ \text { TC } & =\text { Biaya Total }\end{array}$

\section{HASIL DAN PEMBAHASAN}

\section{Identitas Responden}

Responden yang diambil yaitu seorang perajin nata de coco di Desa Bojongmengger Kecamatan Cijeungjing Kabupaten Ciamis. Berdasarkan hasil penelitian di lapangan diketahui bahwa responden bernama Ajat Sudrajat berumur 47 tahun, hal ini sejalan dengan pendapat Matra (2003) yang menyatakan bahwa penduduk usia produktif adalah yang berusia 15-64 tahun.

Pendidikan mempunyai peranan yang sangat penting dan cukup tinggi terhadap seseorang dalam melakukan kegiatan usaha, karena tingkat pendidikan dapat mempengaruhi seseorang dalam pengetahuan dan untuk menerima, melaksanakan hal-hal yang baru. Tingkat pendidikan formal yang dicapai oleh responden adalah Sekolah Menengah Atas (SMA). Menunjukkan bahwa tingkat pendidikan responden relatif tinggi karena mampu melaksanakan wajib belajar 12 tahun.

Pengalaman berusaha yaitu faktor yang sangat menentukan keberhasilan dalam usaha agroindustri nata de coco, semakin lama pengalaman usaha maka akan semakin tinggi keterampilan dan pengetahuan yang dimiliki dalam melakukan proses produksi. Pengalaman 
responden dalam mengusahakan agroindustri nata de coco yaitu 10 tahun. Melihat pengalaman tersebut dapat dikatakan bahwa responden sudah lama dalam menjalankan usahanya.

Tanggungan keluarga yang dimiliki responden sebanyak 4 orang yang terdiri atas istri dan anak. Adanya tanggungan keluarga tentunya akan menjadi motivasi bagi responden untuk dapat meningkatkan usahanya supaya kebutuhan keluarga dapat terpenuhi.

\section{Analisis Agroindustri Nata De Coco}

Analisis agroindustri nata de coco terdiri atas analisis biaya, penerimaan dan pendapatan usaha selama satu kali proses produksi yang dihitung dalam penelitian ini.

Biaya Tetap, Biaya Variabel dan Biaya Total per Satu Kali Proses Produksi pada Agroindustri Nata De Coco Tahun 2019

\begin{tabular}{|c|c|c|c|}
\hline $\begin{array}{l}\mathbf{N} \\
\mathbf{o}\end{array}$ & Jenis biaya & $\begin{array}{c}\text { Jumlah biaya } \\
\text { (Rp) }\end{array}$ & $\%$ \\
\hline \multirow[t]{5}{*}{1} & Biaya Tetap & & \\
\hline & Pajak Bumi, Bangunan dan Perizinan & $1.166,67$ & 0,08 \\
\hline & Penyusutan Alat & $25.507,99$ & 1,80 \\
\hline & Bunga bank Biaya Tetap & 5,33 & 0,0003 \\
\hline & Biaya Tetap Total & $26.679,99$ & \\
\hline \multirow[t]{16}{*}{2} & Biaya Variabel & & \\
\hline & Air Kelapa & $350.000,00$ & 24,72 \\
\hline & Gula Pasir & $180.000,00$ & 12,72 \\
\hline & Cuka & $60.000,00$ & 4,24 \\
\hline & Limbah Tahu & $180.000,00$ & 12,72 \\
\hline & Nanas & $24.000,00$ & 1,70 \\
\hline & Alumunium Sulfat & $75.000,00$ & 5,30 \\
\hline & Kayu Bakar & $15.000,00$ & 1,05 \\
\hline & Listrik & $1.153,85$ & 0,08 \\
\hline & Koran & $8.000,00$ & 0,57 \\
\hline & Karung & $14.000,00$ & 0,99 \\
\hline & Sabun & $1.500,00$ & 0,10 \\
\hline & Transportasi & $25.000,00$ & 1,77 \\
\hline & Bunga Bank Biaya Variabel & 186,73 & 0,01 \\
\hline & Tenaga Kerja & $455.091,00$ & 32,15 \\
\hline & Biaya Variabel Total & $1.388 .931,58$ & \\
\hline 3 & Biaya Total & $1.415 .611,57$ & 100,00 \\
\hline
\end{tabular}

Sumber: Hasil Wawancara, 2019

$\begin{array}{rrr}\text { Untuk } & \text { memperoleh } & \text { nilai } \\ \text { penerimaan } & \text { saat } & \text { penelitian }\end{array}$

agroindustri nata de coco per satu kali proses produksi dihitung dengan cara mengalikan produksi nata de coco dengan harga jual. Lebih jelasnya untuk penerimaan agroindustri nata de coco dapat di lihat pada Tabel.

Produksi, Harga Produk dan Penerimaan Per Satu Kali Proses Produksi pada Agroindustri Nata De Coco Tahun 2019

\begin{tabular}{llr}
\hline No & \multicolumn{1}{c}{ Uraian } & \multicolumn{1}{c}{ Jumlah } \\
\hline 1 & Nata De Coco $(\mathrm{kg})$ & 8.500 \\
2 & Harga Produk $(\mathrm{Rp} / \mathrm{kg})$ & $2.000,00$ \\
3 & Penerimaan $(\mathrm{Rp})$ & $1.700 .000,00$ \\
\hline
\end{tabular}

Sumber: Hasil Wawancara, 2019

Untuk mengetahui besar pendapatan dari agroindustri nata de coco diperoleh dengan mengurangi besarnya penerimaan dengan total biaya produksi. Analisis penerimaan, pendapatan agroindustri nata de coco di Desa Bojongmengger dapat dilihat pada Tabel.

Penerimaan, Biaya Total, Pendapatan per Satu Kali Proses Produksi pada Agroindustri Nata De Coco Tahun 2019

\begin{tabular}{lll}
\hline No & Uraian & Jumlah \\
\hline 1 & Penerimaan (Rp) & $1.700 .000,00$ \\
2 & Biaya Total (Rp) & $1.415 .611,57$ \\
3 & Pendapatan (Rp) & $284.388,43$ \\
\hline Sumber: Hasil Wawancara, 2019 \\
\multicolumn{3}{r}{ Menunjukkan per satu kali proses } \\
\multicolumn{2}{c}{ produksi pada agroindustri nata de coco di }
\end{tabular}
Desa Bojongmengger memperoleh keuntungan dan layak untuk diusahakan. 


\section{KESIMPULAN}

\section{Kesimpulan}

Berdasarkan hasil penelitian dan pembahasan, maka dapat ditarik kesimpulan :

1) Besarnya biaya dalam satu kali proses produksi yang dikeluarkan perajin nata de coco di Desa Bojongmengger adalah Rp 1.415.611,57.

2) Besarnya penerimaan yang diperoleh adalah Rp 1.700.000,00.

3) Besarnya pendapatan adalah $\mathrm{Rp}$ $284.388,43$.

Menunjukkan bahwa usaha agroindustri nata de coco di Desa Bojongmengger memperoleh keuntungan dan layak untuk diusahakan.

\section{Saran}

Agroindustri nata de coco di Desa Bojongmengger dapat memberikan keuntungan, sehingga disarankan untuk mempertahankan, meningkatkan kegiatan usahanya dan kualitas produk. Perajin harus lebih aktif lagi bagi mendapatkan ilmu yang baru seperti mengikuti pelatihan-pelatihan supaya bisa menciptakan dan mengolah tahap selanjutnya hingga bisa memasarkan setelah produk di kemas. Mendorong pengembangan agroindustri nata de coco akan lebih efektif jika didukung dengan penerapan teknologi yang lebih canggih sehingga dapat menghasilkan mutu dan kualitas yang lebih tinggi. Tujuan akhirnya supaya lebih banyak lagi menarik konsumen dan dapat menghadapi pesaing di luar maka usaha akan lebih maju dan pendapatan keuntungan yang lebih tinggi.

\section{DAFTAR PUSTAKA}

Arikunto, S. 2006. Prosedur Penelitian Suatu Pendekatan Praktek. Rineka Cipta. Jakarta.

Dinas Pertanian dan Ketahanan Pangan Kabupaten Ciamis. 2019. Data Luas Areal dan Produksi Kelapa di Kabupaten Ciamis Tahun 2018. Dinas Pertanian dan Ketahanan Pangan Kabupaten Ciamis.Ciamis.

Disperindagkop dan UMKM Kabupaten Ciamis. 2019. Potensi Industri di Kabupaten Ciamis Tahun 2018. Ciamis.

Ismini. 2010. "Analisis Nilai Tambah dan Strategi Pemasaran Kripik Singkong I Perusahaan Mickey Mouse".Agrika. Vol. 4 No 2.

Kecamatan Cijeungjing. 2019. Laporan Tahunan 2018. Kecamatan Cijeungjing Kabupaten Ciamis. Ciamis.

Mantra. 2003. Demografi Umum. Yogyakarta: Puataka Pelajar.

Nazir, M. 2011. Metode Penelitian. Ghalia Indonesia Persada. Bogor.

Suratiyah. 2015. Ilmu Usahatani Edisi Revisi. Penebar Swadaya. Jakarta.

Vita, D. 2016. Kelapa Muda Pelepas dahaga Sejuta Khasiat. Penerbit Stomata. Surabaya.

Windro, A. 2002. Membuat Nata De Coco. PT Panca Anugrah Sakti. Tanggerang Bante 